\title{
PRODUÇÃO CIENTÍFICA SOBRE CULTURA ORGANIZACIONAL E ORÇAMENTO: UMA ANÁLISE BIBLIOMÉTRICA E SOCIOMÉTRICA EM PERIÓDICOS INTERNACIONAIS
}

\author{
Rafaella Maranhão Kawata ${ }^{1}$ \\ Maicon Schnell ${ }^{2}$ \\ Leandro Augusto Toigo ${ }^{3}$ \\ Delci Grapégia Dal Vesco 4
}

\begin{abstract}
RESUMO: A pesquisa tem por objetivo verificar como se apresenta a produção científica internacional sobre cultura organizacional e orçamento. Procurou-se identificar as publicações em relação ao tema organizational cultura and budget devido a ascensão do tema em estudo, no decorrer dos últimos anos. A metodologia da pesquisa está delineada quanto aos objetivos como descritiva, em relação aos procedimentos como documental, quanto à abordagem quantitativa e utilizou-se a análise bibliométrica e sociométrica. O universo do estudo constitui-se das publicações contidas no banco de dados da SCOPUS, com a utilização das palavras-chave "organizational culture" e "budget", disponíveis de acesso via Web, compondo um total de 70 artigos. Os resultados apresentaram uma evolução em número de artigos publicados ao longo dos anos, especialmente a partir do ano de 1995 que o tema cultura organizacional e orçamento passou a ter maior produtividade no meio acadêmico. Observa-se que os pesquisadores do tema sobre cultura organizacional e orçamento, compreendem uma considerável rede cooperação envolvendo vários autores com significativos laços entre si, e também outros pequenas e médias cooperações. No que se refere aos temas relacionados às pesquisas feitas sobre cultura organizacional, observou-se três temas com maior destaque, sendo cultura organizacional, Orçamento e Gestão nas Organizações. Como conclusão do estudo identifica-se que a pesquisa sobre cultura organizacional e orçamento com base na literatura internacional está em ascensão nos últimos anos. Sugere-se para futuras pesquisas que seja feito um estudo mais detalhado sobre a temática envolvendo a literatura nacional e internacional.
\end{abstract}

Palavras-chave: Cultura Organizacional. Orçamento. Bibliometria. Sociometria.

1 Mestre em contabilidade pela UNIOESTE. Professora no Curso de Ciências Contábeis na UNIOESTE de Marechal Cândido Rondon-PR. Graduada em Ciências Contábeis pela UNIOESTE. Universidade Estadual do Oeste do Paraná (UNIOESTE). Paraná. Brasil. E-mail: rafaellakawata@yahoo.com.br

2 Mestre em Contabilidade pela UNOESTE. Universidade Estadual do Oeste do Paraná (UNIOESTE). Paraná. Brasil. E-mail: schnell.adv@hotmail.com

${ }^{3}$ Doutor em Ciências Contábeis e Administração pela FURB. Mestre em Ciências Contábeis pela UNISINOS. Professor do Mestrado em Contabilidade da UNIOESTE. Universidade Estadual do Oeste do Paraná (UNIOESTE). Paraná. Brasil. E-mail: leandro.toigo@unioeste.br

${ }^{4}$ Doutora em Ciências Contábeis e Administração pela FURB. Profa. do Mestrado em Contabilidade da UNIOESTE. Universidade Estadual do Oeste do Paraná (UNIOESTE). Paraná. Brasil. E-mail: delcigrape@gmail.com

Ágora: R. Divulg. Cient., v. 23, n. 1, p. 29-49, jan./jun. 2018 (ISSNe 2237-9010) 


\title{
SCIENTIFIC PRODUCTION ON ORGANIZATIONAL CULTURE AND BUDGET: A BIBLIOMETRIC AND SOCIOMETRIC ANALYSIS IN INTERNATIONAL JOURNALISTS
}

\begin{abstract}
The research aims to verify how the international scientific production on organizational culture and budget is presented. We sought to identify the publications in relation to the topic organizational culture and budget due to the rise of the theme under study in the last years. The methodology of the research is delineated as regards the objectives as descriptive, in relation to the procedures as documentary, regarding the quantitative approach and the bibliometric and sociometric analysis was used. The study universe consists of the publications contained in the SCOPUS database, using the keywords "organizational culture" and "budget", available for web access, making a total of 70 articles. The results showed an evolution in the number of articles published over the years, especially since the year 1995 that the theme organizational culture and budget came to have greater productivity in the academic environment. It is observed that the researchers on the topic of organizational culture and budget, comprise a considerable network of cooperation involving several authors with significant ties to each other, as well as other small and medium cooperations. With regard to the themes related to research on organizational culture, three themes were highlighted. As conclusion of the study it is identified that research on organizational culture and budget based on international literature has been on the rise in recent years. It is suggested for future research that a more detailed study on the theme involving the national and international literature
\end{abstract}

Keywords: Organizational Culture. Budget. Bibliometrics. Sociometrics.

\section{INTRODUÇÃO}

A incerteza que tradicionalmente acompanha as mudanças organizacionais das empresas envolve todo um contexto social e cultural, tornando-se cada vez mais uma tarefa difícil para manter a constância da direção das iniciativas planejadas de suas próprias mudanças organizacionais para as empresas. O pai da administração moderna, Peter Drucker, concluiu que as mudanças organizacionais estão em um desses grandes períodos que ocorrerem a cada 200 ou 300 anos, no momento em que as pessoas não entendem mais o mundo e o passado não é suficiente para explicar o futuro (CAMERON; QUINN, 2005).

Neste sentido, na perspectiva de identificar a caracterização cultural de uma organização, uma parte importante da literatura acadêmica argumenta que o sucesso de muitas empresas foi orientado pelo planejamento definido de suas 
estratégias organizacionais (PORTER, 1980). Por outro lado, a cultura organizacional precede de indivíduos com forte ligação a sua moral, comprometimento com a organização, a produtividade, a saúde física, o bem-estar emocional entre outros (KOZLWISKI; CHAO; SMITH, 1993).

Desta forma, a aplicabilidade da cultura organizacional e sua identificação para cada tipo de organização, a literatura tem observado que ambientes organizacionais sofrem influências na aplicação de processos orçamentários na assimetria informacional, ligado a outras variáveis, como os estudos de Camerron e Quinn (2005), Shields e Young (1993), Dunk (1993), Fischer, Fredericson e Peffer (2002), Tan et al. (2003), Kyj e Parker (2008), Zainuddin et al. (2008), Lavarda e Almeida (2013), Tarifa e Almeida (2016). Lavarda e Almeida (2013) avançaram ao relacionar a influência da participação orçamentária na redução da assimetria informacional e partiram do pressuposto que o orçamento participativo minimiza a assimetria informacional, no entanto os resultados encontrados constataram que tal condição não reduz a assimetria informacional, pois a maioria dos entrevistados possuem mais informações do que seu gerente/supervisor.

Assim, nota-se que até então foram investigadas variáveis relacionadas a cultura organizacional, no entanto não se tem conhecimento de pesquisas de cunho bibliométricas que envolvam cultura organizacional e orçamento. Em relação aos estudos bibliométricos, Araújo (2006) discorre que tal estudo envolve técnica quantitativa e estatística de medição dos índices de produção e disseminação do conhecimento científico. A pesquisa realizada por Mázaro et al. (2015), elencou que a cultura organizacional torna-se cada vez mais relevante a medida que as organizações buscam compreender sua estrutura.

Diante das premissas mencionadas, percebe-se que o tema cultura organizacional e o orçamento estão relacionados por envolverem aspectos que tangem a ambos, nesse intuito, o estudo concentra-se na resposta da seguinte questão: Como se apresenta a produção científica internacional sobre cultura organizacional e orçamento? Assim, o objetivo do artigo é analisar a produção científica internacional sobre cultura organizacional e orçamento por meio de uma análise bibliométrica e sociométrica.

A justificativa do estudo consiste em mapear a literatura internacional ao passo de se perceber uma considerável produção sobre o tema relacionado em 
periódicos internacionais, verificar a estrutura intelectual em que estão conectados e contribuiu para estruturar pesquisas futuras relacionadas a temática, ao passo que não se encontra até o momento, um estudo que demonstre como se apresenta tal produção científica em termos de autores, universidades e temas relacionados sobre cultura organizacional e orçamento. Tal estudo ganha importância ao possibilitar a identificação destes autores e centros de estudos de referência internacional sobre o tema, bem como os assuntos mais discutidos.

\section{REFERENCIAL TEÓRICO}

O presente estudo traz no embasamento teórico os temas relacionados na cultura organizacional, orçamento, bibliometria e redes sociais.

\subsection{CULTURA ORGANIZACIONAL}

Cada organização possui sua identidade própria, que se caracteriza como uma forma social singular, que possui características provenientes do modelo de gestão e perfil adotado pelos seus membros, ou seja, a sua cultura.

Para Schein (1984) a cultura organizacional é o conjunto de pressupostos básicos que um grupo inventou, descobriu e desenvolveu ao aprender como lidar com os problemas de adaptação externa e integração interna e que funcionaram bem o suficiente para serem considerados válidos e ensinados a novos membros como a forma correta de perceber, pensar e sentir em relação a esses problemas. Compreende-se que a cultura de uma empresa está associada tanto a forma individual, coletiva e social dos membros pertencentes à organização e está refletida na maneira em como são realizadas as tarefas.

A cultura organizacional é uma temática que vem sendo discutida por diferentes abordagens, que trazem consigo aspectos sobre o comportamento coletivo e social de seus membros Heinzmann e Lavarda (2011), as dimensões de cultura de Hofstede (1980), interação organizacional de Berger e Luckmann (1967), níveis relacionados às influências internas e externas que formam a estrutura da organização (SCHEIN, 1992). 
Os desafios competitivos enfrentados pelas organizações durante a década de 1960 tornaram popular a cultura organizacional conforme apontado pelos pesquisadores Williamson (1975); Ouchi (1981) e Camerron e Quinn (2005). Esses estudiosos organizacionais identificaram um conjunto alternativo de atividades que justificam a eficácia organizacional, como novo modelo de organização empresarial, no qual é orientado para o ambiente externo, em vez de assuntos internos.

Enquanto o mundo foi se desenvolvendo e deslocado da era industrial para o da informação, fez com que as organizações se preocupassem com valores organizacionais, em que cada tipo de cultura são concentrados com a finalidade de demonstrar o perfil da cultura organizacional da empresa de acordo com a Figura de 1.

Figura 1 - Perfil da Cultura Organizacional

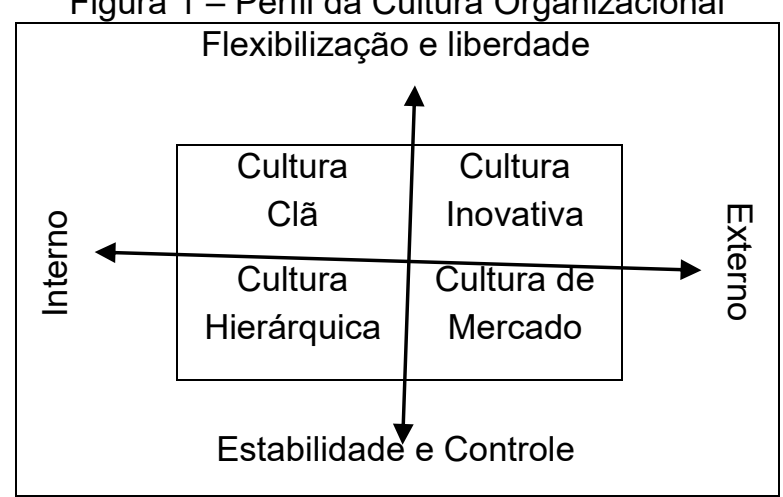

Fonte: Adaptado de Cameron e Quinn (2005)

$\mathrm{Na}$ figura 1, são destacadas como se concentra a manutenção interna com a flexibilidade, a preocupação com as pessoas e sensibilidade para com os clientes, que se concentra no posicionamento externo com um alto grau de flexibilidade e individualidade para uma cultura de mercado. Ademais, denota-se, que a utilidade desse quadro é como uma maneira de diagnosticar e iniciar a mudança na cultura organizacional a mediada que as organizações progridem por meio de seus ciclos de permanência com as pressões de seus ambientes externos (CAMERON; QUINN, 2005).

$\mathrm{Na}$ concepção de Hofstade (1980) a dimensão cultural estabelecida denominada aversão à incerteza para caracterizar a maneira como as sociedades se comportam em relação ao desconhecido, que gera incertezas e riscos e considera que a gestão da incerteza faz parte de todas as instituições em todos os países, pois 
o ser humano tem a ansiedade de não saber o que irá acontecer no dia de amanhã, dada a incerteza do futuro.

\subsection{ORÇAMENTO E PARTICIPAÇÃO ORÇAMENTÁRIA}

O relacionamento entre a cultura organizacional e as práticas contábeis gerenciais nas empresas ainda é objeto de estudo pouco explorado o que amplia a possibilidade de aprofundamento nos temas, visto que as estruturas de crenças, valores e costumes nas organizações formam alicerce e influenciam de forma direta ou indireta as práticas operacionais e administrativas das organizações (TARIFA, 2008).

A prática orçamentária sustenta os mecanismos de controle das organizações, pois é capaz de integrar os processos da organização em um único sumario corrente (OTLEY, 1999). Otley e Pollanen (2000) ainda elencam que quando avaliada como ferramenta de mensuração de performance empresarial, a prática orçamentária é específica a cada organização devido aos aspectos culturais e temporais, ou seja, não existem técnicas de avaliação e gerência de desempenho universais.

A importância da participação do orçamento dos subordinados como um meio de melhorar o desempenho tem sido estudado extensivamente pela contabilidade como Milani (1975); Brownell (1981, 1982); Brownell MCinnes (1986); Chenhall Brownell (1988); Mia (1989); Kyj e Parker (2008); Zainuddin et al. (2008); Lavarda e Almeida (2013); Tarifa e Almeida (2016) Argumenta-se que o ato de participação no processo orçamentário serve como uma função de induzir os subordinados a aceitar e se comprometer com suas metas de orçamento.

Assim, os superiores incentivam a participação orçamentária por vários motivos, entre os quais Kyj e Parker (2008) destacam que as teorias da liderança, da agência e da justiça organizacional descrevem relações comunicativas entre subordinados e informações privadas sobre o poder dos subordinados, sendo que transmitir uma percepção de justiça e equidade para avaliar os subordinados é atendida nos orçamentos. Deste modo, a organização poderá ter uma política de orçamento voltada para a comunicação aberta e informação descentralizada. 


\subsection{BIBLIOMETRIA}

De acordo com Balancieri (2004) a bibliometria pode ser descrita como o estudo dos aspectos quantitativos da produção, disseminação e do uso da informação registrada. Os estudos bibliométricos ainda segundo o autor foram realizados pela primeira vez por Pitchard em 1999. A definição dada por Fonseca (1986) é de que a bibliometria consiste na aplicação da estatística a bibliografia.

As principais leis bibliométricas, conforme Tague-Sutckiffe (1992, apud VANTI, 2002) são Lotka, Zipf e Bradford. A Lei de Lotka ou Lei do Quadro Inverso (1926) aponta para a medição da produtividade dos autores, mediante um modelo de distribuição de tamanho - frequência dos diversos autores, em um conjunto de documentos; a Lei de Bradfor ou Lei da Dispersão (1934) elenca que, mediante a medição da produtividade das revistas é possível estabelecer o núcleo e as áreas de dispersão sobre um determinado assunto em um mesmo conjunto de revistas. Já a Lei de Zipf ou Lei do Mínimo Esforço (1949), consiste em medir a frequência do aparecimento das palavras em vários textos, o que gera uma lista ordenada de termos de uma determinada disciplina ou assunto (TANGUE-SUTCKIFFE, 1992 apud VANTI, 2002).

Os estudos bibliométricos são importantes fontes de informações que auxiliam a predição de enfoques e abrangências futuras da produção científica em determinada área (NICHOLAS; RITCHIE, 1978). Em relação a área contábil, Leite Filho (2008) destaca que os estudos bibliométricos ocorrem no Brasil, no entanto não enfatizam ainda uma análise minuciosa dos padrões de produtividade dos autores, veículos de publicação, instituições e localidades mais citados nos periódicos e anais de congressos específicos da área contábil.

\subsection{REDES SOCIAIS}

Com a tentativa de entender o seu impacto sobre a vida social, a análise de redes sociais vem sendo constantemente utilizada como objeto de estudo em diversos campos do conhecimento e deram origem a inúmeras metodologias de análise que tem como base as relações entre os indivíduos, em uma estrutura em forma de redes (SILVA, et. al., 2006). 
Ditrikson (2003 apud PICCOLI; TOIGO; CUNHA, 2014) dizem que o conhecimento sobre as redes sociais pode auxiliar na compreensão dos processos de interação entre os autores e como ocorre a geração de conhecimento entre eles. Para Sodré (2002, p.14), rede é "onde as conexões e as interseções tomam o lugar do que seria antes pura linearidade".

A sociometria analisa atores sociais e suas relações por meio da representação de um conjunto de nós (atores) e seus laços (relações sociais) (GRANOVETTER et al., 1973). Ainda de acordo com os autores os laços entre atores de uma rede social podem ser de dois tipos: forte ou fraco. O primeiro consiste em uma conexão direta entre atores na qual as informações a serem compartilhadas tendem a ser as mesmas, com baixa tendência para mudança (BURT, 1992). Já o laço fraco refere-se a contatos indiretos formados por meio de pontes, os quais podem fornecer diferentes fontes de informação e tornam a rede propensa à inovação (GRANOVETTER et al., 1973).

Dentre as características existentes em um conjunto de redes existem densidade e centralização. Marsden (1993) elenca que a densidade indica quantos atores dessa rede estão conectados uns aos outros, portanto quanto maior o número de laços fortes entre os atores da rede, maior sua densidade. Já a centralização de acordo com Wasserman e Faust (1994) reflete a centralidade dos atores em suas redes, ou seja, o grau de importância do ator na rede no que toca ao agenciamento entre diferentes atores.

\section{METODOLOGIA}

A metodologia da pesquisa está delineada quanto aos objetivos como descritiva, em relação aos procedimentos como documental, quanto a abordagem quantitativa e utilizou-se a análise bibliométrica e sociométrica. De acordo com Oliveira (2001) a pesquisa bibliométrica é utilizada para quantificar os processos de comunicação escrita e emprego de indicadores bibliométricos para medir a produção científica. O estudo sociométrico de acordo com Wasserman e Galaskiewcz (1994) é voltado a exploração da matriz de relacionamentos estabelecida entre os atores sociais. 
O estudo apresenta como universo de pesquisa, as publicações feitas nos periódicos internacionais que abordavam no título a expressão "organizational culture e budget", avaliados pela SCOPUS, referentes a subárea "business management accounting", dos anos de 1981 a 2016. Sabe-se que a base de dados Web Science é uma opção importante quando se trata de assuntos voltados para o campo de administração, no entanto optou-se por se realizar a busca dos trabalhos contidos na base de dados SCOPUS com o intuito de fazer uma leitura mais precisa dos trabalhos publicados. Em referência a uma leitura precisa, os autores realizaram a leitura do resumo, introdução e conclusões dos trabalhos publicados. Foram encontrados 70 trabalhos essa pesquisa considerou os artigos publicados nas revistas sem a colocação de espaçamento de tempo, ou seja, uma busca aberta. A escolha para o levantamento de dados na base do SCOPUS se deu pelo motivo de ser um portal eletrônico conceituado no que se refere à esfera internacional. A base de dados SCOPUS é uma base multidisciplinar, produzida pela editora Elsevier desde 2004 e com cobertura desde 1960 e o acesso é feito pelo portal da Capes. Tal base de dados ainda possibilita verificar as referências do artigo, número de vezes que $\mathrm{o}$ artigo foi citado e índice $\mathrm{H}$. Inicialmente foram baixados todos os artigos científicos e elaborado um banco de dados, tabulados em planilha eletrônica para a análise bibliométrica e sociométrica. As informações coletadas foram: nome do artigo, tema do artigo, ano de publicação, nome do periódico, nome dos autores, número de citações na base pesquisada até 25 de agosto de 2016 .

A análise de redes deu-se por meio do Software $\mathrm{UCINET}^{\circledR} 6$, levando-se em conta: à associação entre autores segundo a categoria de produção e continuidade; à produção científica por categoria e por ano; à produção científica por periódico e por ano; à rede social dos autores e autores mais prolíficos e com maior quantidade de laços e a classificação dos artigos segundo os temas. Para a elaboração da nuvem de palavras, observou-se as palavras chave contidas nos trabalhos selecionados e utilizou-se o programa WORDLE ${ }^{\circledR}$, disponível on-line. Como principal limitação tem-se a generalização 


\section{DESCRIÇÃO E ANÁLISE DOS RESULTADOS}

Nesta seção apresentam-se a descrição e análise de dados da pesquisa, sendo que na Tabela 1 destaca-se o total de artigos do estudo segregados por periódico mais prolífico sobre "organizational culture and budget", e em conjunto é demonstrada a quantidade de publicações entre os anos de 1981 a 2016. Foram obtidos 70 artigos publicados em periódicos diferentes, envolvendo 131 pesquisadores de 80 universidades de todo o mundo.

Tabela 1 - Número de artigos publicados por periódico

\begin{tabular}{l|c|c|c|c}
\hline \multicolumn{1}{c|}{ PERÍODICOS } & 1981 -1996 & 1997-2006 & 2007-2016 & TOTAL \\
\hline Harvard Business Review & 0 & 4 & 0 & 4 \\
\hline Accounting, Organizations and Society & 2 & 0 & 1 & 3 \\
\hline Journal of Strategic Information Systems & 3 & 0 & 0 & 3 \\
\hline Human Resource Management International Digest & 0 & 0 & 3 & 3 \\
\hline Journal of Marketing & 1 & 1 & & 2 \\
\hline Management Decision & 0 & 0 & 2 & 2 \\
\hline International Journal of Accounting & 1 & 0 & 1 & 2 \\
\hline Industrial and Commercial Training & 0 & 2 & & 2 \\
\hline International Journal of Educational Management & 0 & 1 & 1 & 2 \\
\hline Accounting, Auditing and Accountability Journal & 0 & 0 & 2 & 2 \\
\hline Outros & 6 & 10 & 29 & 45 \\
\hline TOTAL & $\mathbf{1 3}$ & $\mathbf{1 8}$ & $\mathbf{3 9}$ & $\mathbf{7 0}$ \\
\hline
\end{tabular}

Fonte: Elaborado pelos autores.

Nota-se por meio da Tabela 1 quais os periódicos mais prolíficos separados em 3 períodos por critérios de conveniencia, dentre eles destaca-se: Harvard Business Review, com 4 publicações, Accounting, Organizations and Society, com 3 publicações, Journal of Strategic Information Systems, Human Resource Management International Digest, com 3 publicações cada; e Journal of Marketing, Management Decision, International Journal of Accounting, International Journal of Accounting, Industrial and Commercial Training, International Journal of Educational Management, Accounting, Auditing and Accountability Journal, com 2 publicações cada. Complementando a análise da Tabela 1, o Gráfico 1 apresenta o número de publicações: 
Figura 2 - Número de artigos sobre Cultura Organizacional e orçamento publicado por ano (19812016)

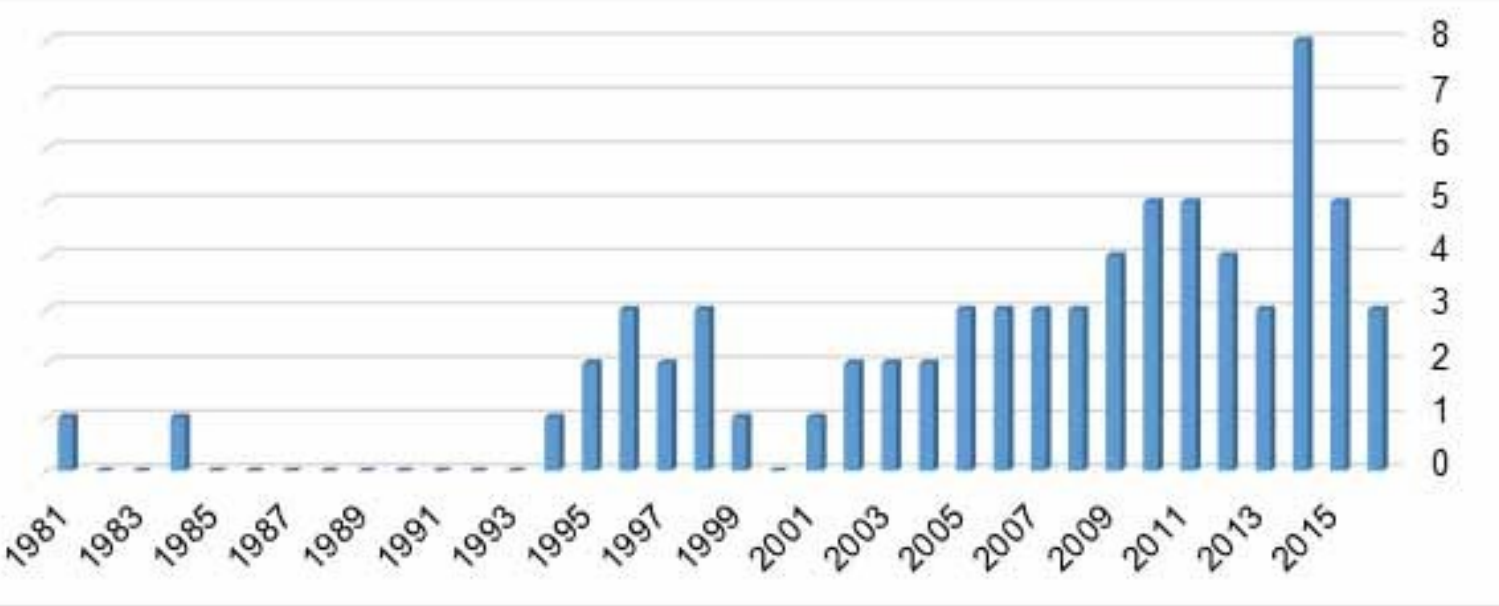

Fonte: Elaborado pelos autores.

De acordo com a Figura 2, no período analisado por ano houve um aumento gradativo e não uniforme do número de artigos publicados, especificamente a partir dos anos de 1995. Este resultado detalha a Tabela 1 e demonstra o aumento das discussões sobre Cultura Organizacional e orçamento no meio acadêmico. Sobre os mesmos artigos, foi realizado o levantamento das citações, sendo que foram apresentados na Tabela 2 para aqueles artigos que apresentavam acima de 10 citações.

Tabela 2 - Quantidade de citações por artigo

\begin{tabular}{l|l|c|c}
\hline \multicolumn{1}{c|}{ Nome do artigo } & \multicolumn{1}{c|}{ Autor } & Ano & Citações \\
\hline $\begin{array}{l}\text { Market situation interpretation and response: The } \\
\text { role of cognitive style, organizational culture, and } \\
\text { information use }\end{array}$ & $\begin{array}{l}\text { WHITE, J.C.; } \\
\text { VARADARAJAN, } \\
\text { P.R.; DACIN, P.A. }\end{array}$ & 2003 & 161 \\
\hline $\begin{array}{l}\text { Management control of public and not-for-profit } \\
\text { activities }\end{array}$ & HOFSTEDE, G. & 1981 & 133 \\
\hline $\begin{array}{l}\text { The influence of organizational culture on the } \\
\text { usefulness of budget participation by Singaporean- } \\
\text { Chinese managers }\end{array}$ & H'CONNOR, N.G. & 1995 & 75 \\
\hline $\begin{array}{l}\text { Who Needs Budgets? } \\
\text { Management control, culture and ethnicity in a a } \\
\text { Chinese Indonesian company }\end{array}$ & $\begin{array}{l}\text { EFFERIN, S., HOPPER, } \\
\text { T. }\end{array}$ & 2007 & 37 \\
\hline $\begin{array}{l}\text { Tipping point leadership. } \\
\text { Regulatory hybrids: Partnerships, budgeting and } \\
\text { modernising government }\end{array}$ & $\begin{array}{l}\text { KURUNMÄKI, } \\
\text { MILLER, P. }\end{array}$ & 2003 & 41 \\
\hline $\begin{array}{l}\text { Distributed leadership in higher education: What } \\
\text { does it accomplish? }\end{array}$ & $\begin{array}{l}\text { GOSLING, J., BOLDEN, } \\
\text { R., PETROV, G. }\end{array}$ & 2011 & 34 \\
\hline $\begin{array}{l}\text { The hidden investments in information technology: } \\
\text { The role of organisational context and system } \\
\text { dependency }\end{array}$ & $\begin{array}{l}\text { HINTON, C.M., KAYE, } \\
\text { G.R. }\end{array}$ & 1996 & 34 \\
\hline
\end{tabular}

Ágora: R. Divulg. Cient., v. 23, n. 1, p. 29-49, jan./jun. 2018 (ISSNe 2237-9010) 
Produção científica sobre cultura organizacional e orçamento: uma análise bibliométrica e sociométrica em periódicos internacionais

\begin{tabular}{l|l|c|c}
\hline $\begin{array}{l}\text { Making just decisions: Organizational justice, } \\
\text { decision making, and leadership }\end{array}$ & $\begin{array}{l}\text { EBERLIN, R.J., TATUM, } \\
\text { C.B. }\end{array}$ & 2008 & 21 \\
\hline $\begin{array}{l}\text { Cultural and ethical effects in budgeting systems: A } \\
\text { comparison of U.S. and Chinese managers }\end{array}$ & $\begin{array}{l}\text { DOUGLAS, P.C., WIER, } \\
\text { B. }\end{array}$ & 2005 & 17 \\
\hline
\end{tabular}

Fonte: Elaborado pelos autores.

$\mathrm{Na}$ Tabela 2, nota-se que $\mathrm{o}$ artigo Market situation interpretation and response: The role of cognitive style, organizational culture, and information use do autor J. Chris White (WHITE, J.C.); P. Rajan Varadarajan (VARADARAJAN, P.R.); Peter A. Dacin (DACIN, P.A.) é o mais citado desde 2003 com 161 citações, sendo que o artigo tem como tema a cultura organizacional, em que a cultura organizacional e uso da informação está ligado a aspectos cognitivos em relação a situação de mercado. Destaca-se que o primeiro artigo sobre Cultura Organizacional, de Geert Hofstede (HOFSTEDE, G.), pela base Scopus, atingiu 133 citações, considerando seminal, apresentando considerável contribuição ao campo de pesquisa sobre o tema, pois, As abordagens tradicionais para o controle de gerenciamento geralmente falham para atividades públicas e sem fins lucrativos.

$\mathrm{Na}$ década de 80 , dois artigos tiveram destaque nas citações. Nos anos 90 merecem destaque, com 75 citações, o artigo de Neale G O'Connor (O'CONNOR, 1995) sobre o tema cultura organizacional sobre a utilidade da participação orçamentária, e no ano de 2003, com 41 citações o artigo de (HOPE; FRASER, 2003). Ademais, os Efferin, S., Hopper, T. (2007); Kim, W.C., Mauborgne, R. (2003); Kurunmäki, L., Miller, P. (2011); Gosling, J., Bolden, R., Petrov, G. (2009); Hinton, C.M., Kaye, G.R. (1996); Eberlin, R.J., Tatum, C.B (2008) e Douglas, P.C., Wier, B (2005), contribuíram para o campo de pesquisa sobre cultura organizacional e orçamento como os artigos mais citados na base de dados SCOPUS.

\subsection{REDES INTERINSTITUCIONAIS}

O desenvolvimento de pesquisa no campo da cultura organizacional e orçamentária, nos últimos 35 anos ocorreu por meio do esforço de 80 instituições de ensino. Dentre estas $35 \%$ são norte-americanas e as demais são do Reino Unido com $17,5 \%$, Australianas, Neozelandesas, Chinesas, Alemãs e outras. A Figura 3 ilustra a rede de cooperação interinstitucional da totalidade de IES envolvidas na 
produção científica. Foram desconsideradas da figura as instituições de ensino que não apresentavam laços.

Figura 3 - Rede de cooperação interinstitucional

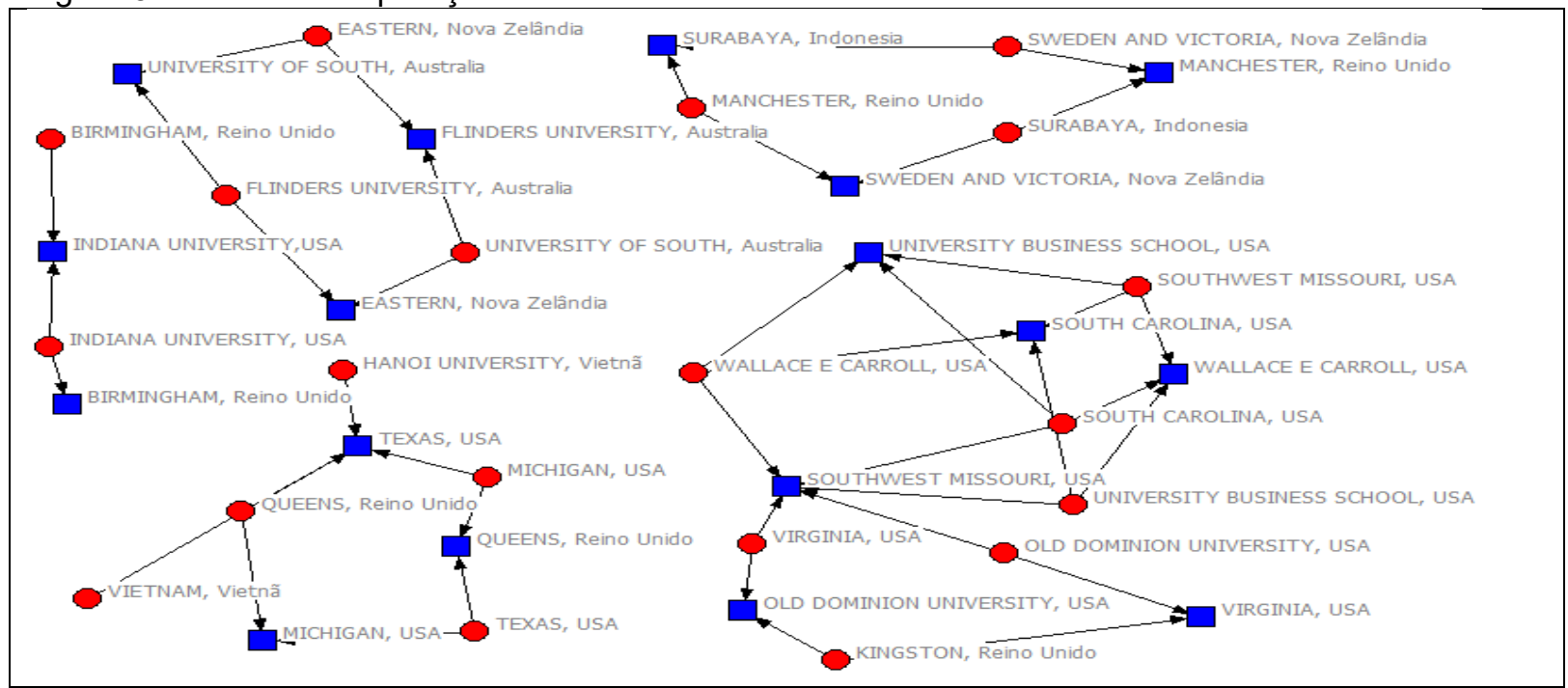

Fonte: Elaborado pelos autores.

Conforme ilustrado na Figura 3 essas são as redes de coautoria por período. Cada nó representa uma publicação, cujos laços expressam relações de autoria neste estudo, os nós são interpretados como pesquisadores que gastam tempo escrevendo artigos. A produtividade de cada nó é em função de suas ligações (JACKSON; WOLINSKY, 1996).

Observa-se na Figura 1 o número de Universidades, entre as quais a norteamericana se destaca entre as demais Instituições de Ensino Superior que pesquisam sobre cultura organizacional e orçamento. Com grau de centralidade MICHIGAN, USA, TEXAS, USA, QUEENS, Reino Unido. Também foi constatado que outras instituições norte-americanas e não norte-americanas apresentam um pequeno número de laços definidos pela relação dos seus pesquisadores, que os atribui certo grau de centralidade. Para complementar esta análise, a Tabela 3 apresenta as instituições de ensino com o maior número de laços observados na Figura 3. 
Produção científica sobre cultura organizacional e orçamento: uma análise bibliométrica e sociométrica em periódicos internacionais

Tabela 3 - Instituições com o maior número de laços

\begin{tabular}{l|c|l|c}
\hline Instituições & Laços & Instituições & Laços \\
\hline VIRGINIA, USA & 4 & MICHIGAN, USA & 2 \\
\hline KINGSTON, Reino Unido & 3 & SWEDEN, Nova Zelândia & 2 \\
\hline SOUTHWEST MISSOURI, USA & 3 & TEXAS, USA & 2 \\
\hline UNIVERSITY BUSINESS SCHOOL, USA & 3 & QUEENS, Reino Unido & 2 \\
\hline WALLACE E CARROLL, USA & 3 & SURABAYA, Indonésia & 2 \\
\hline SOUTH CAROLINA, USA & 2 & MANCHESTER, Reino Unido & 2 \\
\hline
\end{tabular}

Fonte: Elaborado pelos autores.

Para a avaliação dos laços mais representativos observados na Figura $1 \mathrm{e}$ apresentados na Tabela 3 foram consideradas as instituições de ensino que apresentavam acima de 2 laços de produção de conhecimento interinstitucional. Percebeu-se a predominância de universidades norte-americanas fazendo parte de uma rede de produção de conhecimento.

Considerando o Gráfico 1, a Figura 1 e a Tabela 3 é possível inferir que a produção científica acadêmica vem crescendo nos últimos 20 anos e que as universidades norte americanas, até o momento, consolidam-se a frente das demais universidades do resto do mundo, por apresentarem a única rede de grande centralidade sobre o tema. Para melhor interpretação das redes que se formaram nas universidades é necessário observar a formação das redes de coautorias.

\subsection{REDES DE COAUTORIAS}

Em decorrência da rede de cooperação entre autores no campo analisado é observada a estrutura de relacionamentos de 131 pesquisadores/autores proveniente dos periódicos analisados entre o período de 1981 a 2016 conforme está ilustrada, por sua vez, na Figura 4. 
Figura 4 - Rede de Coautorias

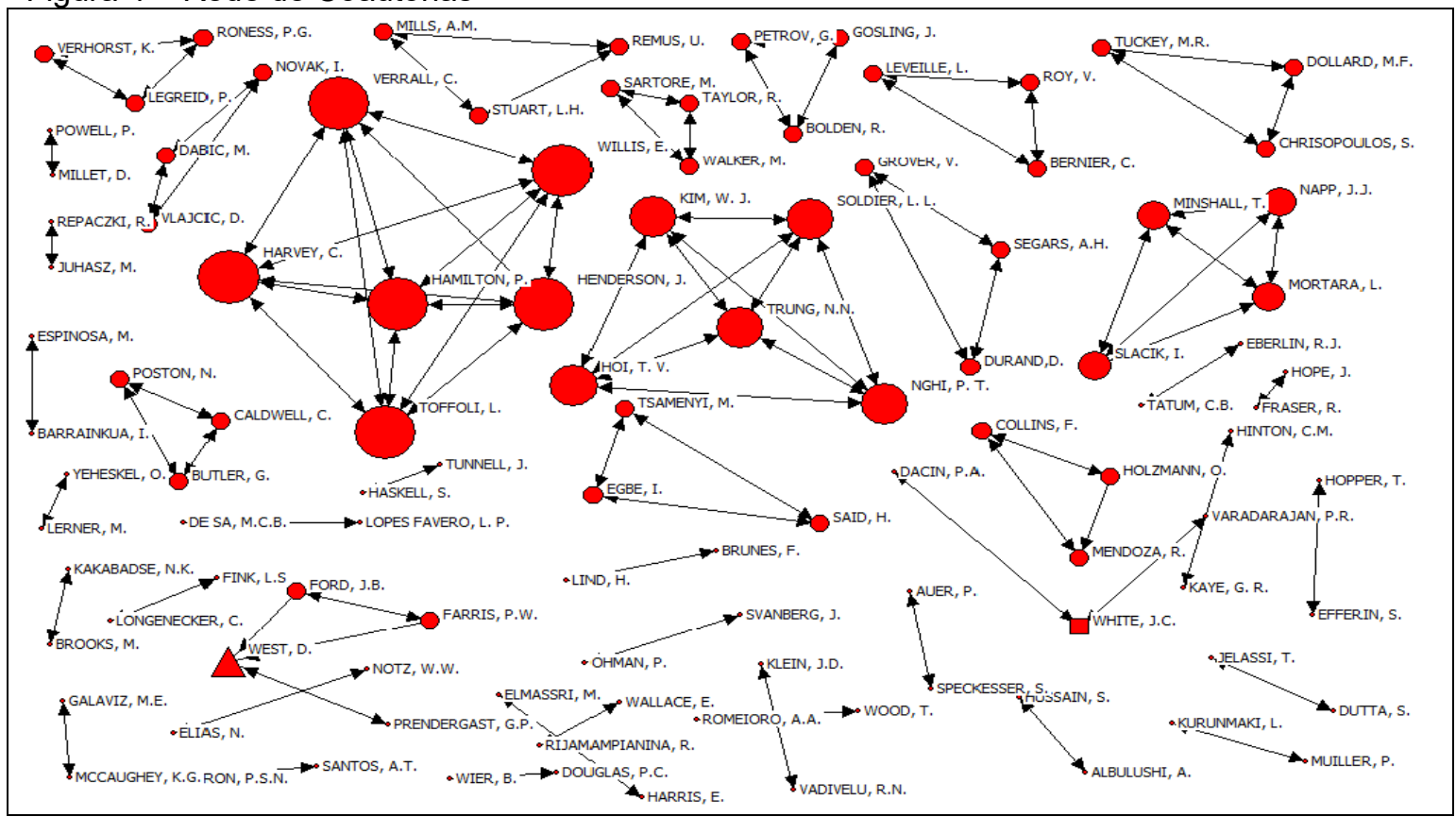

Fonte: Elaborado pelos autores.

Conforme ilustrado na Figura 4, visualiza-se que os pesquisadores do tema sobre cultura organizacional e orçamento, compreende uma considerável rede cooperação envolvendo vários autores com laços entre si, com pequenas e médias cooperações. Em relação à importância de alguns pelo considerável grau de centralidade (deggre) que os mesmos apresentam dentro de uma rede de pesquisa, que pode ser constatado com os autores Patti Hamilton (HAMILTON, P.), Clare Harvey (HARVEY, C.), Jullie Henderson (HENDERSON, J.), Luisa Toffoli (TOFFOLI, L.), Claire Verral (VERRALL, C.) e Eillen Willis (WILLIS, E.). Portanto, estes autores são os que possuem mais laços de coautoria sobre cultura organizacional e orçamento, o que criou uma ligação com vários grupos de pesquisas envolvendo um número considerável de pesquisadores em torno das discussões sobre o tema.

Assim, na Tabela 4 são evidenciados apenas os autores que apresentaram quantitativo igual e superior a 2 laços. E dentre os seis principais atores da rede de cooperação verificasse que os mesmos são professores das universidades norteamericanas e australianas, tais como: de Michigan, USA; Texas, USA e University Of South, Austrália. 
Produção científica sobre cultura organizacional e orçamento: uma análise bibliométrica e sociométrica em periódicos internacionais

Tabela 4 - Número de coautorias

\begin{tabular}{l|c|l|c}
\multicolumn{1}{c|}{ Nome dos autores } & Laços & \multicolumn{1}{c}{ Nome dos autores } & Laços \\
\hline HAMILTON, P. & 5 & EGBE, I. & 2 \\
\hline HARVEY, C. & 5 & FARRIS, P. W. & 2 \\
\hline HENDERSON, J. & 5 & FORD, J. B. & 2 \\
\hline TOFFOLI, L. & 5 & GOSLING, J. & 2 \\
\hline VERRALL, C. & 5 & HOLZMANN, O. & 2 \\
\hline WILLIS, E. & 4 & LEGREID, P. & 2 \\
\hline HOI, T. V. & 4 & LEVEILLE, L. & 2 \\
\hline KIM, W. J. & 4 & MILLS, A. M. & 2 \\
\hline NGHI, P. T. & 4 & NOVAK, I. & 2 \\
\hline SOLDIER, L. L. & 4 & PETROV, G. & 2 \\
\hline TRUNG, N. N. & 3 & POSTON, N. & 2 \\
\hline MORTARA, L. & 3 & RONESS, P. G. & 2 \\
\hline MINSHALL, T. & 3 & REMUS, U. & 2 \\
\hline NAPP, J. J. & 3 & ROY, V. & 2 \\
\hline SLACIK, I. & 2 & SAID, H. & 2 \\
\hline BERNIER, C. & 2 & SARTORE, M. & 2 \\
\hline BOLDEN, R. & 2 & SEGARS, A. H. & 2 \\
\hline BUTLER, G. & 2 & STUART, L. H. & 2 \\
\hline CALDWELL, C. & 2 & TAYLOR, R. & 2 \\
\hline CHRISOPOULOS, S. & 2 & TSAMENYI, M. & 2 \\
\hline COLLINS, F. & 2 & TUCKEY, M. R. & \\
\hline DABIC, M. & 2 & VERHORST, K. & 2 \\
\hline DOLLAD, M. F. & 2 & WALKER, M. & \\
\hline DURAND, D. & & & 2 \\
\hline Fonte: Ela & & 2 \\
\hline
\end{tabular}

Fonte: Elaborado pelos autores.

Para Wasserman e Faust (1994), as redes de coautorias representam a troca de experiências e estudos entre pesquisadores que publicaram nos periódicos. A Figura 4 apresenta a publicação dos pesquisadores, destacando a integração das pesquisas e relacionamentos entre os autores, correspondente a cultura organizacional e orçamento estudado. Observando os autores, percebe-se que há uma escassa rede de relacionamentos entre autores.

Outro ponto importante a considerar foi que, objetivando complementar a análise longitudinal obtida por meio do Gráfico 1, que demonstra os resultados da análise das redes de publicações para o período de 1981 à 2016, foram realizados em período trienal. Os resultados obtidos entre redes de universidades e coautores não apresentaram significativas diferenças do que foi exposto nas Figuras 3 e 4 , exceto pelo processo evolutivo de laços que resultou nas mesmas figuras. 


\subsection{TEMAS ABORDADOS E NUVENS DE PALAVRAS}

Quanto aos temas dos 70 artigos publicados em relação a cultura organizacional e orçamento, destacam-se uma quantidade de 9 temas, sendo descritos conforme Tabela 6 e relacionados com o ano de publicação.

Tabela 6 - Temas mais abordados

\begin{tabular}{l|c|c|l|c|c}
\hline \multicolumn{1}{c|}{ Temas } & Artigos & $\%$ & \multicolumn{1}{c}{ Temas } & Artigos & $\%$ \\
\hline Cultura organizacional & 15 & 21,4 & Sistema de informação & 1 & 1,4 \\
\hline Orçamento & 12 & 17,1 & Relatórios financeiros & 1 & 1,4 \\
\hline Gestão nas Organizações & 7 & 10 & Comunicação & 1 & 1,4 \\
\hline Liderança & 3 & 4,2 & Mercado de trabalho & 1 & 1,4 \\
\hline Tecnologia & 3 & 4,2 & Outros & 26 & 37,1 \\
\hline TOTAL & $\mathbf{4 0}$ & 57,1 & TOTAL & $\mathbf{3 0}$ & 42,9 \\
\hline
\end{tabular}

Fonte: Elaborado pelos autores.

Percebe-se de acordo com a Tabela 6, que a maioria dos artigos encontrados com a palavra chave "organizational culture and budget", relacionam-se com os temas "Cultura organizacional", "orçamento" e "Gestão nas Organizações" foram os temas que mais geraram publicações nos períodos analisados, especificamente $48,5 \%$ das publicações, os quais são possíveis de considerar a espinha dorsal dos debates sobre cultura organizacional e orçamento nos últimos 35 anos. A Figura 5 apresenta as palavras-chaves mais citadas no tema dos 70 artigos explorados entre os anos de 1981 a 2016.

Figura 5 - Nuvem de Palavras do Tema

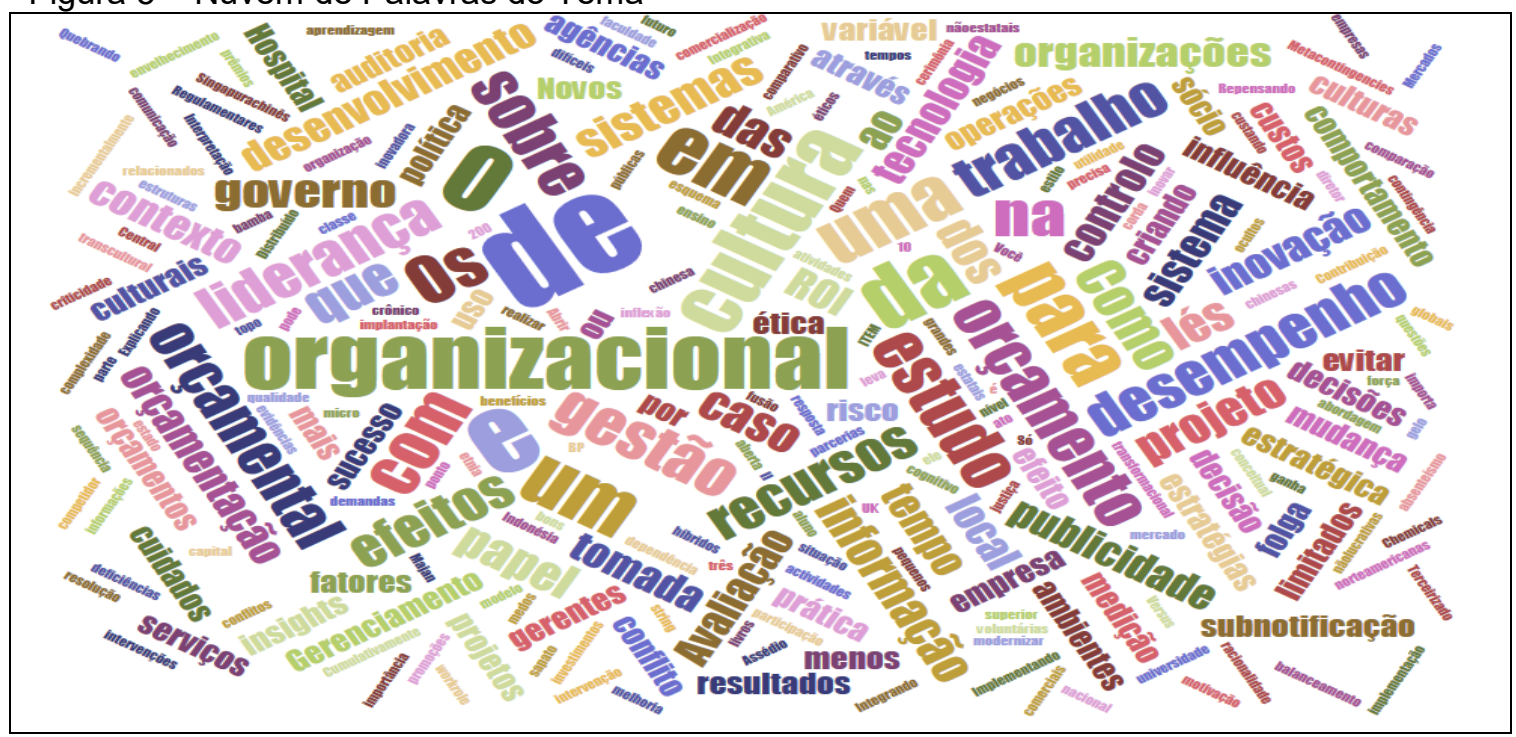

Fonte: Elaborada pelos autores.

Ágora: R. Divulg. Cient., v. 23, n. 1, p. 29-49, jan./jun. 2018 (ISSNe 2237-9010) 
Com a análise da Figura 5, as palavras que se destacam nos artigos pesquisados são: cultura organizacional, orçamento, gestão, tecnologia, informação, publicidade entre outras. Com estes resultados, verifica-se a ocorrência da Lei de Zipf, a qual apura a frequência de palavras, com os objetivos de identificar ou informar o tema científico mais visado nos artigos.

\section{CONSIDERAÇÕES FINAIS}

O objetivo do estudo consistiu em realizar uma análise bibliométrica e sociométrica de como se encontra a produção científica internacional em relação a cultura organizacional e orçamento. $O$ total de artigos segregados por periódico mais prolífico; a quantidade de publicações no período; à produção científica por categoria e por ano; à produção científica por periódico e por ano; à rede social dos autores e autores mais prolíficos e com maior quantidade de laços e a classificação dos artigos segundo os temas mais relevantes na construção do conhecimento.

Por meio dos resultados é possível perceber que o campo de pesquisa em cultura organizacional e orçamento no âmbito internacional encontram-se consolidado, com pesquisas em locais e organizações distintas, no entanto, com possibilidade de melhoria em relação ao fortalecimento de redes de co-autoria.

Diante dos resultados apresentados, as limitações do presente estudo linha de pesquisa relacionada ao tema cultura organizacional e orçamento explorados apenas na base de dados SCOPUS. Sugere-se para futuras pesquisas ampliar a base de dados, incluindo a base da web of Science e também desenvolver uma revisão sistemática sobre o assunto relacionados à cultura organizacional e orçamento.

\section{REFERÊNCIAS}

ARAÚJO, Carlos AA. Bibliometria: evolução histórica e questões atuais. Em questão, v. 12, n. 1, 2007.

BALANCIERI, R. Análise de redes de pesquisa em uma plataforma de gestão em ciência e tecnologia: uma aplicação à Plataforma Lattes. 2004. Dissertação (Mestrado) - UFSC, Florianópolis, 2004. 
BERGER, P. L.; LUCKMANN, T. A. The social construction of reality. New York: Doubleday, 1967.

. Construção social da realidade. Petrópolis: Vozes, 1996.

BROWNELL, P. The role of budgets in organizations facing strategic change: an exploratory study. Accounting, Organizations and Society, v. 24, n. 3, p. 189-204, 1999.

; MCINNES, M. Budgetary participation, motivation, and managerial performance. Acc. Rev., p. 587-600, 1986.

CAMERON, K. S.; QUINN, R. E. Diagnosing and changing organizational culture: based on the competing values framework. Michigan: Addison-Wesley. 1998.

; Diagnosing and changing organizational culture: based on the competing values framework. John Wiley \& Sons, 2005.

CHENHALL, R. H. Management control systems design within its organizational context: findings from contingency-based research and directions for the future.

Accounting, Organization and Society, Londres, v. 28, n. 2-3, p. 127-168, 2003.

CHIAVENATO, I. Comportamento organizacional: a teoria e a prática de inovar. Rio de Janeiro: Campos, 2005.

CHOW, C. W.; COOPER, J. C.; WALLER, W. Participative budgeting: effects of a truthinducing pay scheme and information asymmetry on slack and performance. The accounting Review, v. 63, n. 1, p. 111-122, 1988.

et al. The balanced scorecard: a potent tool for energizing and focusing healthcare organization management. Journal of Healthcare Management, v. 43, n. 3, p. 263-280, 1998.

DIDRIKSSON, A. La sociedad del conocimiento desde la perspectiva latino americana. In: ENCUENTRO DE ESTUDIOS PROSPECTIVOS REGIÓN ANDINA: SOCIEDAD, EDUCACIÓNY, 4., 2003, Medellín. Anais... Colômbia: ESUMER, 2003.

DUNK, A. S. The effect of budget emphasis and information asymmetry on the relation between budgetary participation and slack. The accounting Review, v. 68, n. 2, p. 400-410, abr. 1993.

; PERERA, $\mathrm{H}$. The incident of budgetary slack: a field study exploration.

Accounting, Auditing and Accountability Journal, v. 10, n. 5, p. 649-664, 1997.

FONSECA, E. N. Bibliometria: teoria e prática. São Paulo: Cultrix, 1986. 
FORESTI, N. Estudo da contribuição das revistas brasileiras de biblioteconomia e ciência da informação enquanto fonte de referência para a pesquisa. 1989. Dissertação (Mestrado) - UnB, Brasília, 1989.

GALASKIEWICZ, J.; WASSERMAN, S. Advances in social network analysis: research in the social and behavioral sciences. London: Sage, 1994.

GRANOVETTER, M. The Strength of Weak Ties. American Journal of Sociology, v. 78, n. 6,1973, p. $1360-1380$.

HEINZMANN, L. M.; LAVARDA, C. E. F. Cultura organizacional e o processo de planejamento e controle orçamentário. Revista de Contabilidade e Organizações, v. 5, n. 13, p. $4-19,2011$.

HOFSTEDE, G. Culture's consequences: international differences in work-related values. Sage Publications, 1980. v. 5.

Culture and organizations: software of the mind, intercultural cooperation and its importance for survival. London: Harper Collins, 1994.

JENSEN, M. C.; MECKLING, W. H. Theory of the firm: managerial behavior, agency costs and ownership structure. Journal of Financial Economics, v. 3, n. 4, p. 305360 , oct. 1976.

KYJ, L.; PARKER, R. J. Antecedents of Budget Participation: leadership style, information asymmetry, and evaluative use of budget. ABACUS, v. 44, n. 4, p. 423442, 2008.

LAVARDA., C. E. F; ALMEIDA, D. M. Participação orçamentária e assimetria informacional: um estudo em uma empresa multinacional. BBR-Brazilian Business Review, v. 10, n. 2, p. 74-96, 2013.

LEITE FILHO, G. A. Padrões de produtividade de autores em periódicos e congressos na área de contabilidade no Brasil: um estudo bibliométrico. Revista de Administração Contemporânea, Curitiba, v. 12, n. 2, abr./jun. 2008.

MARSDEN, P. V. The reliability of network density and composition measures. Social Networks, v. 15, n. 4, p. 399- 421, 1993.

MILANI, K. The relationship of participation in budget-setting to industrial supervisor performance and attitudes: a field study. The Accounting Review, v. 50, n. 2, p. 274-284, abr. 1975.

MURRAY, D. The performance effects of participative budgeting: an integration of intervening and moderating variables. Behavioral Research in Accounting, p. 104123, 1990.

NICHOLAS, D.; RITCHIE, M. Literature and bibliometrics. C. Bingley: Linnet Books, 1978. 
OTLEY, D. Performance management: a framework for management control systems research. Management Accounting Research, v. 10, p. 363-382, 1999.

; POLLANEN, Raili M. Budgetary criteria in performance evaluation: a critical appraisal using new evidence. Accounting, Organizations and Society, v. 25, p. 483-496, 2000.

SCHEIN, E. H. Coming to a new awareness of organizational culture. Sloan Management Review, Winter, p. 3-16, 1984.

Organizational culture and leader ship. 2. ed. San Francisco: JosseyBass Publishers, 1992.

SILVA, A. B. O. et al. Análise de redes sociais como metodologia de apoio para a discussão da interdisciplinaridade na ciência da informação. Revista Ciência da Informação, v.35, n. 1. Brasília, jan./abr. 2006. Disponível em: Acesso em: 26 ago. 2016

SOUZA, C. M. et.al. Bibliometria em cultura organizacional: um levantamento nos eventos da ANPAD. Perspectivas em psicologia, v.19, n. 2, 2015.

TARIFA, M. R. Cultura organizacional e práticas orçamentárias: um estudo empírico nas maiores empresas do sul do brasil. Dissertação (Mestrado em Contabilidade) - Universidade Federal do Paraná, Curitiba, 2008.

WASSERMAN, S.; FAUST, K. Social network analysis: methods and applications. Cambridge: Cambridge University Press, 1994.

ZAINUDDIN, Y. et al. The consequences of information asymmetry, task and environmental uncertainty on budget participation: evidence from Malaysian managers. Int. J. Managerial and Financial Accounting, v. 1, n. 1, p. 97-114, 2008.

Artigo recebido em: 14/10/2017

Artigo aprovado em: 08/06/2018

Artigo publicado em: 01/10/2018 